\title{
Phase I safety trial of intravenous ascorbic acid in patients with severe sepsis
}

\author{
Alpha A Fowler $\| I^{1 *}$, Aamer A Syed ${ }^{1}$, Shelley Knowlson ${ }^{2}$, Robin Sculthorpe ${ }^{3}$, Don Farthing ${ }^{4}$, Christine DeWilde ${ }^{1}$, \\ Christine A Farthing ${ }^{4}$, Terri L Larus ${ }^{4}$, Erika Martin ${ }^{5}$, Donald F Brophy ${ }^{5}$, Seema Gupta ${ }^{6}$, Medical Respiratory Intensive \\ Care Unit Nursing ${ }^{2}$, Bernard J Fisher ${ }^{1}$ and Ramesh Natarajan ${ }^{1}$
}

\begin{abstract}
Background: Parenterally administered ascorbic acid modulates sepsis-induced inflammation and coagulation in experimental animal models. The objective of this randomized, double-blind, placebo-controlled, phase I trial was to determine the safety of intravenously infused ascorbic acid in patients with severe sepsis.

Methods: Twenty-four patients with severe sepsis in the medical intensive care unit were randomized 1:1:1 to receive intravenous infusions every six hours for four days of ascorbic acid: Lo-AscA (50 mg/kg/24 h, n= 8), or Hi-AscA ( $200 \mathrm{mg} / \mathrm{kg} / 24 \mathrm{~h}, \mathrm{n}=8$ ), or Placebo ( $5 \%$ dextrose/water, $\mathrm{n}=8$ ). The primary end points were ascorbic acid safety and tolerability, assessed as treatment-related adverse-event frequency and severity. Patients were monitored for worsened arterial hypotension, tachycardia, hypernatremia, and nausea or vomiting. In addition Sequential Organ Failure Assessment (SOFA) scores and plasma levels of ascorbic acid, C-reactive protein, procalcitonin, and thrombomodulin were monitored.

Results: Mean plasma ascorbic acid levels at entry for the entire cohort were 17.9 $\pm 2.4 \mu \mathrm{M}$ (normal range 50-70 $\mu \mathrm{M}$ ). Ascorbic acid infusion rapidly and significantly increased plasma ascorbic acid levels. No adverse safety events were observed in ascorbic acid-infused patients. Patients receiving ascorbic acid exhibited prompt reductions in SOFA scores while placebo patients exhibited no such reduction. Ascorbic acid significantly reduced the proinflammatory biomarkers C-reactive protein and procalcitonin. Unlike placebo patients, thrombomodulin in ascorbic acid infused patients exhibited no significant rise, suggesting attenuation of vascular endothelial injury.
\end{abstract}

Conclusions: Intravenous ascorbic acid infusion was safe and well tolerated in this study and may positively impact the extent of multiple organ failure and biomarkers of inflammation and endothelial injury.

Trial registration: ClinicalTrials.gov identifier NCT01434121.

Keywords: Ascorbic acid, Biological markers, Clinical trials phase I as topic, Multiple organ failure, Organ dysfunction scores, Sepsis

\section{Background}

The incidence of sepsis and sepsis-associated organ failure continues to rise in Intensive Care Units worldwide with studies from multiple countries showing that organ failure contributes cumulatively to patient mortality [1-3]. Patients with severe sepsis suffer higher mortality rates compared to patients with organ failure but no sepsis. Despite over

\footnotetext{
* Correspondence: afowler@mcvh-vcu.edu

'Division of Pulmonary Disease and Critical Care Medicine, Department of Internal Medicine, School of Medicine, Virginia Commonwealth University, PO Box 980050, Richmond, VA 23298-0050, USA

Full list of author information is available at the end of the article
}

15,000 patients studied and over 1 billion dollars in study costs effective sepsis therapy remains elusive $[4,5]$. Clinical trials that have targeted mediators of inflammation or coagulation such as atorvastatin [6] or activated protein $C$ [7] have not reduced septic mortality, suggesting that single-target therapy fails to meet the challenges of complex multicellular activation and interactions.

Recent studies suggest that ascorbic acid may attenuate pathological responses in septic microvasculature. Armour et al. and Wu et al. showed that ascorbic acid infusion improved capillary blood flow, microvascular barrier function, 
and arteriolar responsiveness to vasoconstrictors in septic animals $[8,9]$. Recently, we showed that parenterally infusing ascorbic acid at a concentration of $200 \mathrm{mg} / \mathrm{kg}$ attenuated vascular lung injury in septic mice by multiple mechanisms, including attenuation of the proinflammatory mediators, enhanced alveolar epithelial barrier function, increased alveolar fluid clearance, and prevention of sepsisinduced coagulopathy $[10,11]$. In addition, ascorbic acid deficient mice were found to be more susceptible to sepsis-induced multiple organ dysfunction and parenteral infusion of ascorbic acid attenuated the injury (lung, kidney, liver) [12].

Subnormal plasma ascorbic acid concentrations in septic patients correlate inversely with the incidence of multiple organ failure and directly with survival [13]. Ascorbic acid depletion in sepsis results from: 1) ascorbic acid consumption by reduction of plasma free iron, 2) ascorbic acid consumption by the scavenging of aqueous free radicals, and 3) by destruction of the oxidized form of ascorbic acid, dehydroascorbic acid [14]. Dosing and bio-distribution data in humans show that pharmacological concentrations of ascorbic acid can only be attained following intravenous administration [15]. Surprisingly, few studies in critically ill patients infusing ascorbic acid have been performed. Nathens and colleagues infused ascorbic acid at 1 gram every 8 hours combined with oral vitamin $\mathrm{E}$ for 28 days in 594 surgically critically ill patients and found a significantly lower incidence of acute lung injury and multiple organ failure [16]. Tanaka et al. infused ascorbic acid continuously at $66 \mathrm{mg} / \mathrm{kg} / \mathrm{hour}$ for the first 24 hours in patients with greater than $50 \%$ surface area burns and showed significantly reduced burn capillary permeability [17]. A single report (published as abstract only) of a clinical study of large intravenous doses of ascorbic acid, and other antioxidants (tocopherol, $\mathrm{N}$-acetyl-cysteine, selenium), in patients with established ARDS showed a 50\% reduction in mortality [18]. Clinical protocols currently in use for hospitalized septic patients fail to normalize ascorbic acid levels. Ascorbic acid dosages utilized in this trial arose from our preclinical work.

In the current trial, we sought to determine whether intravenous ascorbic acid was safe to administer to critically ill patients with severe sepsis and to determine if ascorbic acid had an impact on organ failure and a priori selected blood biomarkers. We measured C-reactive protein and procalcitonin as systemic markers of inflammation while choosing thrombomodulin as a marker of vascular injury [19-21]. The work reported in this study has previously been presented at the American Thoracic Society International Meeting [22].

\section{Methods}

This study was approved by the VCU Institutional Review Board (IRB). The IRB approval number assigned to this trial was: HM12903. The trial was conducted under a randomized double blind placebo-controlled format. A multi-departmental data safety monitoring board oversaw the trial.

\section{Patient enrollment}

Patients were screened and enrolled following admission to the Medical Respiratory Intensive Care Unit in the VCU Medical Center, Richmond, Virginia. Severe sepsis was defined as: 1) Presence of a systemic inflammatory response: (fever: $>38^{\circ} \mathrm{C}$ or hypothermia: $<36^{\circ} \mathrm{C}$ (core temp only), heart rate $>90$ beats $/ \mathrm{min}$, leukocytosis: $>12,000 \mathrm{WBC} / \mu \mathrm{L}$ or leukopenia: $<4,000 \mathrm{WBC} / \mu \mathrm{L}$ or $>10 \%$ band forms) [23], 2) Suspected or proven infection, and 3) Presence of sepsisinduced organ dysfunction: Arterial hypoxemia $\left(\mathrm{P}_{\mathrm{a}} \mathrm{O}_{2} /\right.$ $\mathrm{F}_{\mathrm{i}} \mathrm{O}_{2}<300$ ), systolic blood pressure (SBP) $<90 \mathrm{~mm} \mathrm{Hg}$ or SBP decrease $>40 \mathrm{~mm} \mathrm{Hg}$ unexplained by other causes, Lactate $>2.5 \mathrm{mMol} / \mathrm{L}$ Urine output $<0.5 \mathrm{ml} / \mathrm{kg} /$ hour for greater than two hours despite fluid resuscitation, platelet count $<100,000$, acutely developing coagulopathy (INR $>$ 1.5), Bilirubin $>2 \mathrm{mg} / \mathrm{dL}$. If these three criteria were met within 48 hours of ICU admission, informed consent was obtained from family members of patients deemed eligible for the study. Study groups in this trial were 1) Placebo: $5 \%$ dextrose and water; 2) Low dose ascorbic acid (Lo-AscA): $50 \mathrm{mg} / \mathrm{kg} / 24$ hours; or 3) High dose ascorbic acid (HiAscA): $200 \mathrm{mg} / \mathrm{kg} / 24$ hours. Ascorbic acid dosage was divided into 4 equal doses and administered over $30 \mathrm{mi}$ nutes every 6 hours for 96 hours in $50 \mathrm{ml}$ of $5 \%$ dextrose and water. Study drug infusion was initiated 2 to 4 hours following informed consent and randomization.

The study blind was established and maintained by the VCU Investigational Pharmacy Department where the study drug was prepared, hooded, and dispensed. Subjects were assigned to one of three dosing groups $(0 \mathrm{mg} / \mathrm{kg} /$ day, $50 \mathrm{mg} / \mathrm{kg} /$ day, or $200 \mathrm{mg} / \mathrm{kg} /$ day) in a 1:1:1 ratio using a randomization scheme generated by using Research Randomizer [24]. Placebo or study drug was prepared in $50 \mathrm{~mL}$ polyvinyl chloride intravenous infusion bags (Viaflex, Baxter Healthcare, Deerfield, IL). Ascorbic Acid Injection, USP, (Bioniche Pharma, Lake Forest, IL) was used. Ascorbic acid or placebo solutions were prepared in matching volumes with amber shrouding for light protection and to preserve the blind. Air was removed from IV bags for protection against ascorbic acid oxidation. Ascorbic acid was stored at $2-8^{\circ} \mathrm{C}$ for up to 24 hours prior to use. Preliminary experiments showed no oxidation under these brief storage conditions.

\section{Study data management}

Collected data was managed using REDCap (Research Electronic Data Capture), a secure, web-based data collection and storage tool hosted at VCU [25]. 


\section{Assessment of organ failure}

Organ failure was assessed using the Sequential Organ Failure Assessment (SOFA) score described by Vincent and colleagues [26]. Scores were calculated at enrollment and at 24, 48, 72, and 96 hours given the predictive value of serial SOFA scores reported by Ferreira et al. [27]. Laboratory data and physiologic measures for calculating SOFA scores were monitored daily and recorded into REDCap. Data was normalized using the delta total SOFA score (total maximum SOFA score at study entry minus total maximum SOFA score over the 4-day study period) $[28,29]$.

\section{Study drug infusion and safety monitoring}

Vital signs were monitored every 5 minutes during infusion and every 5 minutes for 45 minutes afterwards by bedside Medical Respiratory Intensive Care Unit (MRICU) Nursing and the investigative team. Patient safety in this Phase I trial was paramount. Four objective indices were monitored during and after ascorbic acid infusion: 1) Hypotension: Defined as a fall in mean arterial blood pressure of $20 \mathrm{~mm} \mathrm{Hg}$ during or following infusion, 2) Tachycardia: Defined as an increase in heart rate of 20 beats per minute during or following infusion, 3) Hypernatremia: Standard of care utilizes $0.9 \%$ saline for volume resuscitation. L-Ascorbic acid preparation used for this study presented a minor sodium load, therefore a potential for hypernatremia to develop existed and 4) Nausea or vomiting: were monitored both during and after ascorbic acid administration by investigators and by MRICU nursing staff. If one of the adverse events listed above was observed, ICU nursing was equipped with bedside algorithms designed to manage the adverse event. If an event was observed, drug infusion was halted. If the event resolved, drug infusion was restarted at $50 \%$ of the original infusion rate. If the event recurred, the patient was removed from the study. If no adverse event was observed, patients were infused for 4 days. Patients were then followed clinically for 28 days.

\section{Blood samples}

Whole venous blood was drawn into sterile Vacutainer ${ }^{\circ}$ tubes (Becton, Dickinson \& Co., Franklin Lakes, NJ): serum tube (BD 367812, red top, clot activator) and plasma tube (lavender top, BD 367861, K2EDTA). Serum samples were allowed to coagulate for $60 \mathrm{~min}$ at room temperature. Plasma and serum were separated by centrifugation. An aliquot of freshly isolated plasma was processed for ascorbic acid analysis. Remaining plasma and serum were aliquoted and frozen at $-70^{\circ} \mathrm{C}$ until assayed.

\section{Plasma ascorbic acid measurement}

Plasma Ascorbic Acid Stability: Preliminary work optimized conditions for stabilizing ascorbic acid in EDTA plasma samples. Briefly, $0.4 \mathrm{ml}$ of cold $20 \%$ trichloroacetic acid
(TCA) and $0.4 \mathrm{ml}$ of cold $0.2 \%$ dithiothreitol (DTT) were added to $0.2 \mathrm{ml}$ of plasma, vortexed for $2 \mathrm{~min}$, and centrifuged $\left(10,000 \mathrm{~g}, 10 \mathrm{~min}, 4^{\circ} \mathrm{C}\right)$. Supernatants were aliquoted and frozen at $-70^{\circ} \mathrm{C}$ for batch analysis. Quality control samples consisted of normal plasma spiked with ascorbic acid (100\& 1,000 $\mu \mathrm{M})$, processed in the same manner, and stored with patient samples. Plasma Ascorbic Acid Concentrations: Plasma ascorbic acid levels were quantified in all patients at enrollment then just prior to administration of the 12, 24, 36, 48, 72, and 96 hour ascorbic acid dosing. Concentrations were measured using high pressure liquid chromatography (HPLC) with UV detection. Chromatography was performed on an Onyx Monolithic C18 Column $(100 \times 4.6 \mathrm{~mm}$; Phenomenex, Torrance, CA) with a mobile phase using a gradient buffer (dipotassium phosphate), ion pairing reagent (tretrabutyl amonium chloride), and acetonitrile at a flow rate $0.8 \mathrm{ml} /$ min. Detection was at $265 \mathrm{~nm}$ and ascorbic acid levels quantified using peak area analysis and external standardization. Ascorbic acid standards $(0-1,000 \mu \mathrm{M})$ were freshly prepared and treated in the same way as the test plasma samples.

\section{Biomarkers}

Biomarkers measured for this study were identified prior to the start of the study. C-Reactive Protein (CRP): A high sensitivity C-reactive protein (hsCRP) assay was performed in collaboration with Health Diagnostics Laboratories, Richmond, Virginia using the Roche hsCRP kit (catalog \# 11972855216) on a Roche automated chemistry analyzer. Procalcitonin (PCT): Procalcitonin levels were quantified using a sandwich ELISA kit according to manufacturer's instructions (RayBiotech, Inc., Norcross, GA). Thrombomodulin (TM): Plasma levels were quantified using an enzymelinked immunosorbent assay kit (IMUBIND; American Diagnostica Inc., Stamford, Connecticut, USA). Samples were incubated in microwells precoated with a monoclonal antibody specific for human thrombomodulin.

See Additional file 1 for description of methods utilized for biomarker analysis.

\section{Statistical analysis}

All analyses in this study were pre-specified. Statistical analysis was performed using SAS 9.3 and Graphpad PRISM 6.0. The results are expressed as means \pm SE. Differences between and within groups were analyzed using two-factor analysis of variance with Tukey's studentized range test. Summary data is reported as mean \pm SEM. Statistical significance was confirmed at a p value of $<0.05$. Organ dysfunction analysis was based on the evolution (slopes) of the delta daily total SOFA score (change in daily total SOFA score compared with day 0) over 4 study days by comparing the regression coefficients using Student's t-test [28,29]. 


\section{Results}

\section{Enrolled study patients}

Over a one year period, 35 patients were screened and 26 patients were enrolled. Reasons for excluding the 9 patients are as follows: a) 3 patients had terminal cancer and were not expected to survive for 24 hours; b) Informed consent could not be obtained in two homeless septic patients, and c) family members refused consent in 4 patients. Eight were enrolled in the placebo group, 8 enrolled in the Lo-AscA group, and 10 enrolled in the $\mathrm{Hi}$-AscA. One patient in the Hi-AscA group was withdrawn by family members and transferred to another institution. One other Hi-AscA patient was withdrawn after Hemophagocytic Syndrome plus sepsis was recognized. These two patients are not included in the analysis. All patients received full ICU standard of care support. Table 1 shows the demographics of enrolled patients. The APACHE II and SOFA scores between groups were statistically identical. Table 2 indicates the underlying diagnosis for patients entered into the trial, the organ system affected, the source and identification of organisms in the patients, and on day one of entry into the trial whether acute kidney injury or respiratory failure was present. Secondary outcomes (i.e., days on vasopressor, Ventilator days, ICU length of stay and 28 day mortality) are now reported in Additional file 2: Table S1. The cohort of patients in this trial had a high incidence of respiratory failure. Nineteen patients had ARDS at entry as defined by the Berlin Definition with $\mathrm{P}_{\mathrm{a}} \mathrm{O}_{2} / \mathrm{F}_{\mathrm{i}} \mathrm{O}_{2}$ (PF) ratios of less than 300 and patchy airspace disease on chest imaging. Five patients had PF ratios above 300 . Of the group with PF ratios above 300 only two were not intubated for ventilatory support. One patient in the group with PF ratios above 300 eventually fell below 300 and satisfied the Berlin Definition of ARDS.

\section{Safety of intravenous ascorbic acid}

Safety of ascorbic acid infusion in critically ill patients was a primary endpoint for this Phase I safety trial. During the 96-hour infusion period, no patients were withdrawn due to study-related adverse events (i.e., hypotension, tachycardia, hypernatremia, or nausea/vomiting). Infusions were halted in one septic patient (Hi-AscA) following infusion \#14 (84 hours) for a ventricular arrhythmia later

Table 1 Baseline demographic data of septic patients treated or not treated with intravenous ascorbic acid

\begin{tabular}{lllll}
\hline Treatment & Gender & Age & $\begin{array}{l}\text { APACHE II } \\
\text { score }^{\mathbf{a}}\end{array}$ & $\begin{array}{l}\text { SOFA } \\
\text { score }^{\mathbf{b}}\end{array}$ \\
\hline Placebo & 4 male 4 female & $54-68$ years & $20.4(15-29)$ & $13.3 \pm 2.9$ \\
Lo-AscA & 5 male 3 female & $30-70$ years & $20.4(12-23)$ & $10.1 \pm 2.0$ \\
Hi-AscA & 4 male 4 female & $49-92$ years & $24.0(12-33)$ & $10.8 \pm 4.4$ \\
\hline
\end{tabular}

${ }^{a} A P A C H E$ Acute Physiology and Chronic Health Evaluation, mean (range).

${ }^{\mathrm{b}} \mathrm{SOFA}$ Sequential Organ Failure Assessment, mean $\pm \mathrm{SE}$. determined by Cardiology consultants to be electrical artifact. This patient is included in the analysis.

\section{Plasma ascorbic acid levels}

Plasma ascorbic acid levels in all septic patients at enrollment were subnormal (i.e., hyposcorbic) at $17.9 \pm 2.4 \mu \mathrm{M}$ (normal $50-70 \mu \mathrm{M}$ ) and were not significantly different at baseline (Figure 1). Ascorbic acid levels in the placebo group fell from $20.2(11-45) \mu \mathrm{M}$ at entry to 15.6 (7-27) $\mu \mathrm{M}$ on study day 4. Ascorbic acid levels increased 20-fold in the low dose treatment group from 16.7 (14-28) $\mu \mathrm{M}$ at baseline to $331(110-806) \mu \mathrm{m}$ on day 4. Ascorbic acid levels increased dramatically in $\mathrm{Hi}$-AscA patients from $17.0(11-50) \mu \mathrm{M}$ at baseline to $3,082(1,592-5,722) \mu \mathrm{m}$ on day 4 . Thus, ascorbic acid levels rose rapidly in the two treatment groups and were significantly higher than placebo within twelve hours (Lo-AscA vs. placebo $\mathrm{p}<0.005$, $\mathrm{Hi}-\mathrm{AscA}$ vs. placebo $\mathrm{p}<0.0005)$ remaining consistently elevated for the 96-hour infusion period. Furthermore, ascorbic acid levels in the Hi-AscA group were significantly higher $(\mathrm{p}<0.005)$ than the Lo-AscA group from the 12 hour point forward reaching millimolar concentrations. These data confirm "hyposcorbic" levels present in untreated human sepsis and show that intermittent ascorbic acid infusion every 6 hours produces sustained steady-state plasma levels.

\section{Impact of ascorbic acid infusion on organ failure}

SOFA scores at enrollment were: Placebo $-13.3 \pm 2.9$, Lo-AscA - 10.1 \pm 2.0 , and Hi-AscA $10.8 \pm 4.4$ and were not significantly different across groups. The components of the SOFA score are listed in Additional file 3: Table S2. Following normalization of the daily SOFA scores, patients treated with either dose of ascorbic acid exhibited descending SOFA scores over the 4-day study period ( $\mathrm{p}<0.05$, slopes significantly non-zero). High dose ascorbic acid patients exhibited significantly faster declines in the regression slopes of delta daily total SOFA scores over time compared to placebo $(-0.043$ vs. $0.003, \mathrm{p}<0.01)$ (Figure 2$)$. Placebo patients exhibited a gradual rise in SOFA scores. Though the cohort size is limited, these data suggest that ascorbic acid infusion significantly attenuates the systemic organ injury associated with sepsis.

\section{Impact of ascorbic acid infusion on biomarkers}

Serum/plasma obtained from enrolled subjects were analyzed for three biomarkers: C-reactive protein (CRP), procalcitonin (PCT), and thrombomodulin (TM). CRP and PCT were quantified as surrogates for inflammation while TM was employed as a surrogate for endothelial injury. At enrollment, biomarker levels across the three groups were not significantly different. Serum CRP trended slowly down over the 96 hour period in the placebo group. Patients receiving ascorbic acid exhibited rapid reductions in 
Table 2 Clinical data on patients with severe sepsis

\begin{tabular}{|c|c|c|c|c|}
\hline Underlying conditions & Source of sepsis & Organism & Renal failure? & Respiratory failure? \\
\hline \multirow[t]{2}{*}{ Lung cancer } & \multirow[t]{2}{*}{ Pneumonia } & Blood: E.coli, Strep bovis & \multirow[t]{2}{*}{ no } & \multirow[t]{2}{*}{ yes } \\
\hline & & Resp: E.coli & & \\
\hline \multirow{2}{*}{$\begin{array}{l}\text { Prodrome with nausea and } \\
\text { vomiting for } 7 \text { days }\end{array}$} & \multirow[t]{2}{*}{ Pneumonia } & Blood: culture negative & \multirow[t]{2}{*}{ no } & \multirow[t]{2}{*}{ yes } \\
\hline & & Urine: Legionella antigen positive & & \\
\hline ETOH cirrhosis & $\begin{array}{l}\text { Spontaneous bacterial } \\
\text { peritonitis }\end{array}$ & Blood: culture negative & no & yes \\
\hline Status/Post gastric bypass & Urinary tract infection & Blood: E. Coli & no & yes \\
\hline \multirow{2}{*}{$\begin{array}{l}\text { Obstructive nephrolithiasis } \\
\text { pyelonephritis }\end{array}$} & \multirow[t]{2}{*}{ Urinary tract infection } & Blood: E.Coli & \multirow[t]{2}{*}{ no } & \multirow[t]{2}{*}{ yes } \\
\hline & & Urine: E.Coli & & \\
\hline End stage renal disease & Catheter sepsis & Blood: MRSA & yes (prior to admission) & yes \\
\hline \multirow{2}{*}{$\begin{array}{l}\text { Acute myelogenous } \\
\text { leukemia (relapse) }\end{array}$} & \multirow[t]{2}{*}{ Portacath sepsis } & Blood: MRSA & \multirow[t]{2}{*}{ no } & \multirow[t]{2}{*}{ yes } \\
\hline & & Urine: Enterobacter & & \\
\hline \multirow[t]{2}{*}{ Influenza } & \multirow{2}{*}{$\begin{array}{l}\text { Pneumonia with } \\
\text { coexistent Influenza A }\end{array}$} & Blood: Strep pneumonia & \multirow[t]{2}{*}{ no } & \multirow[t]{2}{*}{ yes } \\
\hline & & Resp: Influenza A & & \\
\hline Diabetes mellitus & \multirow{3}{*}{$\begin{array}{l}\text { Infected diabetic foot } \\
\text { ulcer }\end{array}$} & Blood: Staph aureus & \multirow[t]{3}{*}{ no } & \multirow[t]{3}{*}{ yes } \\
\hline Chronic kidney disease & & Body Fluid: Staph aureus & & \\
\hline Gout & & Resp: MRSA & & \\
\hline \multirow[t]{2}{*}{ Head and neck cancer } & \multirow[t]{2}{*}{ Pneumonia } & Blood: culture negative & \multirow[t]{2}{*}{ no } & yes \\
\hline & & Resp: culture negative & & \\
\hline Diabetes mellitus & Pneumonia and colitis & Blood: culture negative & yes (dialysis required) & yes \\
\hline Congestive heart failure & & & & \\
\hline Gastrointestinal hemorrhage & & Resp: MRSA & & \\
\hline Cellulitis & Pneumonia & Blood: Group a strep. & no & no \\
\hline Hypercholesterolemia & Urinary tract infection & & & \\
\hline Multiple myeloma & PneumoniaUrinary tract & Blood: Gram positive cocci & no & yes \\
\hline & intectio & Urine: Proteus mirabilis & & \\
\hline Non-Hodgkins lymphoma & Pancreatitis & Resp: Aspergillus fumigatus & no & yes \\
\hline Bone marrow transplant & Intra-abdominal sepsis & Blood: Gram negative rods, & no & yes \\
\hline Bowel perforation & & & & \\
\hline $\begin{array}{l}\text { Post allogeneic bone marrow } \\
\text { transplant }\end{array}$ & Pneumonia & Blood: culture negative & no & yes \\
\hline Chronic opiate use & Aspiration pneumonia & Blood: Strep. pneumonia & no & yes \\
\hline Found obtunded & & $\begin{array}{l}\text { Resp: Strep. pneumonia, } \\
\text { Candida glabrata }\end{array}$ & & \\
\hline Diabetes mellitus & Aspiration pneumonia & Resp: Gram negative rods, & yes (prior to admission) & yes \\
\hline End stage renal disease & & & & \\
\hline Chronic obstructive pulmonary & Pneumonia & Blood: culture negative & no & yes \\
\hline & & $\begin{array}{l}\text { Resp: Acinetobacter, } \\
\text { Stenotrophomonas maltiphilia }\end{array}$ & & \\
\hline Toxic epidermal necrolysis & Skin & Blood: MRSA & yes & yes \\
\hline Acute renal failure & & & & \\
\hline Alcoholic cirrhosis & Subacute bacterial & Blood: culture negative & no & no \\
\hline Hepatorenal syndrome & & & & \\
\hline $\begin{array}{l}\text { Chronic obstructive pulmonary } \\
\text { disease }\end{array}$ & Pneumonia & Blood: Gram positive rods & no & yes \\
\hline Severe ankylosing spondylitis & Urinary tract infection & Blood: Klebsiella pneumonia & no & yes \\
\hline
\end{tabular}


Table 2 Clinical data on patients with severe sepsis (Continued)

\begin{tabular}{llll}
\hline Severe aortic stenosis & & Urine: Klebsiella pneumonia & \\
Hepatitis C cirrhosis & Health care acquired & Blood: culture negative & yes (dialysis required) \\
Esophageal varicies & pneumonia & Urine: Enterococcus & yes \\
Systemic mastocytosis & Pneumonia & Blood: culture negative & yes \\
Congestive heart failure & & Resp: Budding yeast with & pseudohyphae \\
& & no & \\
\hline
\end{tabular}

CRP levels achieving significantly lower levels when compared to their own baseline and placebo by 24 hours (Figure 3A, $\mathrm{p}<0.05)$. PCT levels trended higher in placeboinfused patients 24 hours following the onset of sepsis though not reaching statistical significance. Serum PCT levels in patients receiving high dose ascorbic acid declined, becoming significantly lower than baseline by 48 hours (Figure $3 \mathrm{~B}, \mathrm{p}<0.05$ ). PCT in patients receiving high dose ascorbic acid continued to decline over the 96-hour period. Plasma TM levels in patients randomized to placebo were not different from the ascorbic acid groups at baseline. Placebo patients began to trend upwards beyond 36 hours, remaining elevated when compared to ascorbic acid treated patients though the values were not statistically significant (Figure 4). Importantly ascorbic acid treated patients did not exhibit the upward trend in TM levels observed in

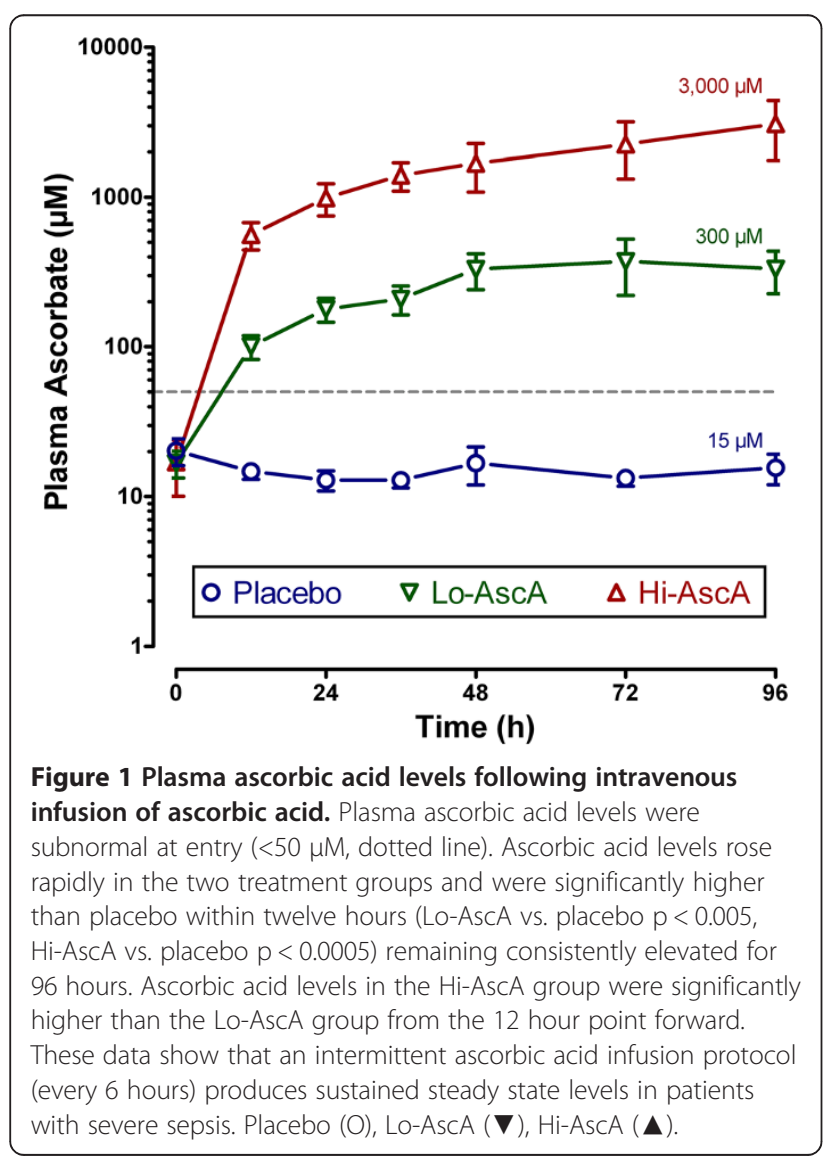

placebo-infused patients. These results suggest that ascorbic acid infusion produces early reductions in proinflammatory mediators in patients with severe sepsis. The results further suggest that ascorbic acid infusion attenuates the evolution of endothelial injury characteristic of severe sepsis in humans.

\section{Discussion}

This phase I trial focused on the safety of administering intravenous ascorbic acid to patients with severe sepsis. The intravenous route of administration was chosen in this trial in order to achieve high ascorbic acid plasma levels. Padayatty and colleagues showed that high-level ascorbic acid plasma concentrations could only be achieved by intravenous administration [15]. Prior human studies employing pharmacologic ascorbic acid dosing report no adverse events. Nathens et al. administered 1 gram of ascorbic acid every 8 hours for 28 days to surgically critically ill patients with no ill effects [16]. Tanaka et al. administered $66 \mathrm{mg} / \mathrm{kg} /$ hour for 24 hours to patients with $50 \%$

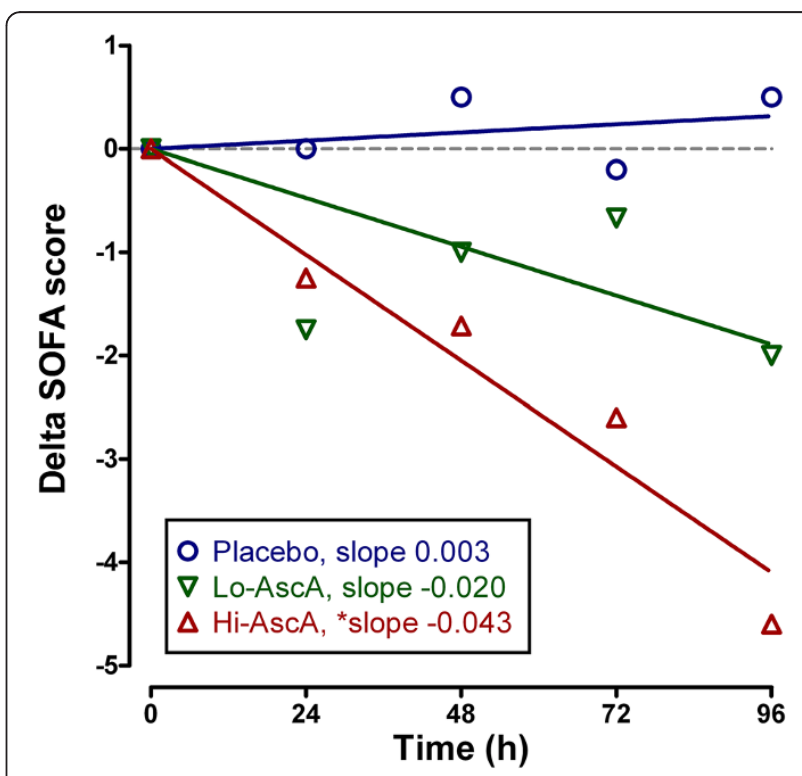

Figure 2 Effect of ascorbic acid infusion on Sequential Organ Failure Assessment (SOFA) score (days 0-4). Daily mean SOFA scores decreased over time with both doses of ascorbic acid infusion ( $p<0.05$ significantly non-zero) with the higher dose significantly less than placebo (Hi-AscA vs. placebo $p<0.01$ ). Placebo $(0)$, Lo-AscA $(\mathbf{\nabla})$, $\mathrm{Hi}-\operatorname{AscA}(\boldsymbol{\Lambda})$. 

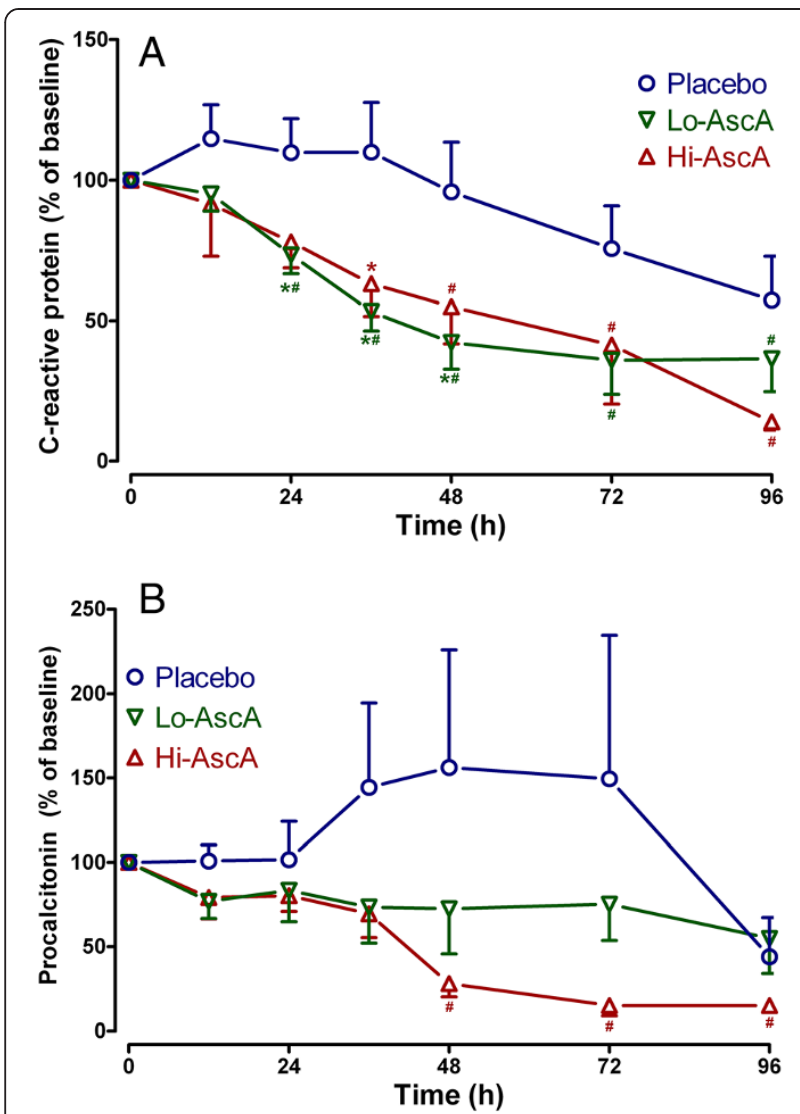

Figure 3 Serum C-reactive protein (CRP) and procalcitonin levels in septic placebo controls and ascorbic acid infused patients. (A) Both the Lo-AscA and the Hi-AscA dosages produced rapid reductions in serum CRP levels, becoming significantly lower than placebo ( ${ }^{*} p<0.05$ vs placebo) as early as 24 hours. Ascorbic acid infusion reduced CRP levels in both groups throughout the 4 study days (\#p $<0.05$ vs 0 hr). CRP levels in placebo patients slowly fell over the course of the 4 day study period. (B) Patients in the Lo-AsCA and Hi-AscA groups exhibited reduced serum PCT levels beginning at 12 hours. Patients in the Hi-VitC group exhibited further significant reduction in serum PCT between 36 to 48 hours (\#p < 0.05 vs 0 hr). Placebo patients exhibited a trend towards increased $\mathrm{PCT}$ levels which declined starting at 72 hours post onset of sepsis. Placebo (O), Lo-AsCA ( $\mathbf{\nabla})$, Hi-AsCA ( $\mathbf{\Delta})$.

surface area burns with no adverse events [17]. Hoffer et al. intravenously administered up to 90 grams of ascorbic acid 3 times weekly to patients with advanced malignancy with no adverse events [30]. The dosing protocols we chose for this trial arose out of our preclinical work.

No patient in the low or high dose ascorbic acid treatment arms of this study suffered any identifiable adverse event. As noted above, the one instance in which ascorbic acid infusion was halted for a cardiac rhythm disturbance was determined to be artifact by the Division of Cardiology. Thus, a pharmacologic ascorbic acid treatment strategy in critically ill patients with severe sepsis appears to be safe.

Prior studies show that patients with severe sepsis exhibit significantly reduced plasma ascorbic acid levels upon

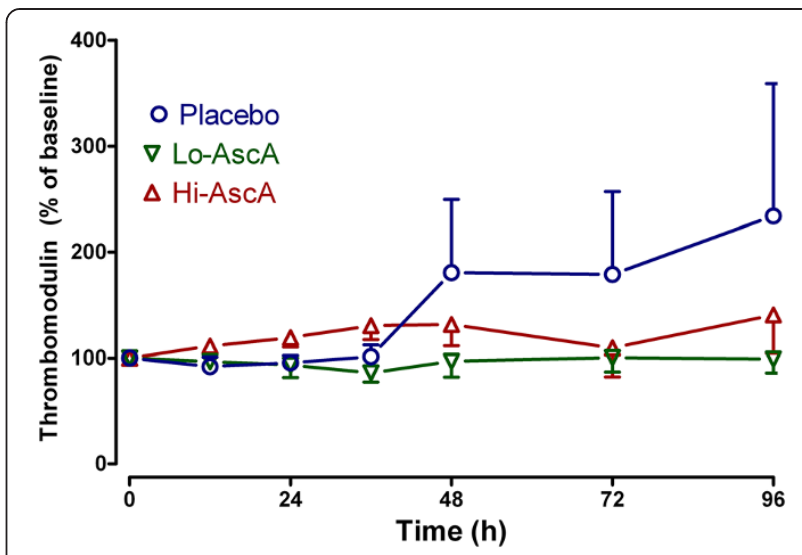

Figure 4 Plasma thrombomodulin (TM) levels measured in septic placebo controls and ascorbic acid infused patients. Plasma TM levels measured in the ascorbic acid infused patients exhibited no rise throughout the 4 days of study. Patients in the placebo group showed a trend towards increased plasma TM levels beginning at 36 hours, though it did not achieve statistical significance. Placebo (O), Lo-AscA ( $\mathbf{\nabla})$, Hi-AscA ( $\mathbf{\Delta})$.

admission to intensive care [31]. The mean initial plasma ascorbic acid level for all septic patients in this study was $17.9 \pm 2.4 \mu \mathrm{M}$ compared to normal human plasma levels of $50-70 \mu \mathrm{M}$ (Figure 1). Prior studies [13,14,26], and the current study show that subnormal plasma ascorbic acid levels are a predictable feature in patients with severe sepsis. Importantly, Placebo patients exhibited no change in plasma ascorbic acid levels throughout the 4-day study period despite receiving full ICU standard of care practice for severe sepsis (Figure 1). Ascorbic acid depletion in sepsis results from ascorbic acid consumption by the reduction of plasma free iron, ascorbic acid consumption by the scavenging of aqueous free radicals (peroxyl radicals), and by the destruction of the oxidized form of ascorbic acid dehydroascorbic acid [14]. Sepsis further inhibits intracellular reduction of dehydroascorbic acid, producing acute intracellular ascorbic acid depletion. Sepsis-induced ascorbic acid destruction permits uncontrolled oxidant activity which amplifies tissue injury $[14,32,33]$. Ascorbic acid treated patients in this study exhibited rapid and sustained increases in plasma ascorbic acid levels using an intermittent every six hours administration protocol (Figure 1).

SOFA scores are robust indicators of mortality during critical illness. SOFA score increases during the first 48 hours of ICU care predict a mortality rate of at least $50 \%$ [26]. In this study, the extent of organ failure accompanying patients with severe sepsis was high with an average SOFA score for all patients equal to $11.4 \pm 3$ confirming that multiple organ failure was present at enrollment. Given that the mean plasma ascorbic acid levels on admission were subnormal $(17.9 \pm 2.4 \mu \mathrm{M})$, a mean initial SOFA score of $11.4 \pm 3$ in patients with severe sepsis was not 
surprising. This study is in agreement with other studies which show that plasma ascorbic acid levels in severe sepsis correlate inversely with the incidence of multiple organ failure [13]. We showed that the addition of ascorbic acid to standard of care practice (i.e., fluid resuscitation, antibiotics, vasopressor medication) for patients with severe sepsis significantly reduced organ injury. Ascorbic acid treated patients exhibited prompt and sustained reductions in SOFA scores during the 4-day treatment regimen unlike placebo controls where SOFA scores slowly increased over time. SOFA score reduction was most remarkable in patients receiving the high dose ascorbic acid infusion (Figure 2).

C-reactive protein (CRP) [19] and procalcitonin (PCT) [20] levels are known to correlate with the overall extent of infection and higher levels of both have both been linked to higher incidences of organ injury and death in the critically ill. CRP in circulation has a short half-life of approximately 19 hours. Thus, the kinetics of CRP make it a useful monitor for tracking the inflammatory response produced by infection, and the response to antibiotic treatment. Lobo et al. reported that patients with CRP levels greater than $10 \mathrm{mg} / \mathrm{dL}$ at ICU admission exhibited significantly higher rates of multiple organ failure as well as higher mortality rates [34]. A decrease in CRP levels in Lobo's study after 48 hours was associated with a mortality rate of only $15.4 \%$, while a persistently high CRP level was associated with a mortality rate of $60.9 \%$. Both low and high dose ascorbic acid infusion in this trial promptly reduced serum CRP levels in septic patients (Figure 3A). Thus, the findings in this study support the findings of Lobo et al. with descending CRP levels being associated with lower mortality rate and reduced levels or organ failure. Jensen and colleagues found that high maximal procalcitonin levels were an early independent predictor of all-cause mortality in a 90-day followup period after intensive care unit admission [20]. Karlsson and colleagues [21] showed that mortality in patients with severe sepsis was lower in those patients in whom procalcitonin concentrations fell by more than $50 \%$ at 72 hours with respect to initial values. Infusion of ascorbic acid into patients with severe sepsis in this study reduced serum procalcitonin levels by greater than 50\% (Figure 3B). Thrombomodulin is an endothelial cell bound molecule that captures thrombin holding it adjacent to protein $\mathrm{C}$ bound to its receptor (endothelial protein $C$ receptor). Elevated soluble TM in the circulation indicates endothelial cell injury [35]. Lin et al. reported that increased TM levels correlated with the extent of organ failure and mortality in patients with sepsis [36]. In the current study, thrombomodulin levels in patients randomized to placebo began to rise at approximately 36 hours into the study period, indicating sepsis-induced endothelial injury (Figure 4). Patients randomized to receive either dose of ascorbic acid exhibited no subsequent rise in plasma thrombomodulin. Though our patient numbers were small, these early results suggest that intravenous ascorbic acid acts to attenuate the proinflammatory state of sepsis and perhaps attenuates the development of endothelial injury.

On the basis of this study and our prior preclinical studies, we speculate as to the pleiotropic mechanisms by which ascorbic acid would be beneficial in sepsis. Ascorbic acid is rapidly taken up by endothelial cells in millimolar quantities where it scavenges reactive oxygen species and increases endothelial nitric oxide synthase-derived nitric oxide by restoring tetrahydrobiopterin content, thus, increasing bioavailable nitric oxide. As we and others have shown in basic investigations $[10,11,37]$, by inhibiting NF $\kappa$ B activation, ascorbic acid could potentially attenuate the "cytokine storm" that arises due to NFKB driven genes known to be activated in sepsis. Septic ascorbic acid-deficient neutrophils fail to undergo normal apoptosis. Rather, they undergo necrosis thereby releasing hydrolytic enzymes in tissue beds, thus contributing to organ injury. We speculate that intravenous ascorbic acid acts to restore neutrophil ascorbic acid levels. Repletion of ascorbic acid in this way allows for normal apoptosis, thus, preventing the release of organ damaging hydrolytic enzymes. A multitude of biological mechanisms are active in patients with sepsis and they promote multiple organ injury and death.

Tens of thousands of lives are lost across the world annually due to severe sepsis [1,38-40]. Multiple treatment trials have failed to measurably improve outcomes. The majority of trials have singly eliminated certain proinflammatory mediators which research has suggested promotes tissue damage. The single mediator approach has largely been unsuccessful. The results from this small phase I safety trial suggest that administering ascorbic acid in pharmacological dosages to critically ill patients with sepsis is safe and that it may provide adjunctive therapy in the treatment of severe sepsis. A larger phase II proofof-concept trial is needed.

\section{Conclusions}

This phase I trial shows that aggressive repletion of plasma ascorbic acid levels in patients with severe sepsis is safe. This early work in septic patients suggests that pharmacologic ascorbic acid repletion reduces the extent of multiple organ failure and attenuates circulating injury biomarker levels.

\section{Additional files}

Additional file 1: Patient Flow Diagram. Flow diagram of the progress through the phases of the safety trial (enrollment, allocation, follow-up, and analysis). 
Additional file 2: Table S1. Secondary outcomes of septic patients treated or not treated with intravenous ascorbic acid. Includes days on vasopressor, ventilator free days, ICU length of stay, and 28-day mortality.

Additional file 3: Table S2: Components of the Sequential Organ Failure Assessment (SOFA) scoring system. Describes the clinical parameters of the scoring system.

\section{Abbreviations}

AscA: Ascorbic acid; CRP: C-reactive protein; PCT: Procalcitonin; SOFA: Sequential organ failure assessment; TM: Thrombomodulin.

\section{Competing interests}

The authors declare that they have no competing interests.

\section{Authors' contributions}

AAF, RN, BJF, AAS: Hypothesis/delineation. AAF, AAS, DF, RS, SK, CD: Study design. AAF, AAS, RN, BJF, DF, CAF, TLL, CD, SG, EM, DFB, MRICU Nursing: Acquisition of data/analysis. AAF, RN, BJF, DF, RS: Interpretation of data/ writing the article. AAF, RN, AAS, and BJF conceived, designed, or planned the study, interpreted the results, and wrote sections of the initial draft. DF, $C A F$, and TLL designed, validated and performed the plasma ascorbic acid HPLC analysis. SK, CD aided in study design and data collection. RS helped design the study and wrote sections of the initial draft. SG supervised biomarker analysis and interpretation of results. EM and DFB provided substantial review and suggestions of the initial draft. All authors read and approved the final manuscript.

\section{Acknowledgement}

The authors wish to acknowledge support for this phase I trial from: 1) The Aubrey Sage Macfarlane Acute Lung Injury Fund, 2) VCU Clinical and Translational Science Award UL1TR000058 from the National Center for Advancing Translational Sciences, 3) VCU Investigational Pharmacy Services, 4) The Jeffress Memorial Trust, and 5) The AD Williams Trust.

\section{Author details}

'Division of Pulmonary Disease and Critical Care Medicine, Department of Internal Medicine, School of Medicine, Virginia Commonwealth University, PO Box 980050, Richmond, VA 23298-0050, USA. ²Department of Critical Care Nursing, Virginia Commonwealth University Health System, Richmond, Virginia, USA. Investigational Drug Services, Department of Pharmacy Services, School of Pharmacy, Virginia Commonwealth University, Richmond, Virginia, USA. ${ }^{4}$ Division of Nephrology, Department of Internal Medicine, School of Medicine, Virginia Commonwealth University, Richmond, Virginia, USA. ${ }^{5}$ Department of Pharmacotherapy \& Outcomes Science, School of Pharmacy, Virginia Commonwealth University, Richmond, Virginia, USA. ${ }^{6}$ Health Diagnostic Laboratory, Richmond, Virginia, USA.

\section{Received: 12 November 2013 Accepted: 2 January 2014}

Published: 31 January 2014

\section{References}

1. Martin GS, Mannino DM, Eaton S, Moss M: The epidemiology of sepsis in the United States from 1979 through 2000. N Engl I Med 2003, 348(16):1546-1554. doi: 10.1056/NEJMoa022139. PMID: 12700374.

2. Quenot JP, Binquet C, Kara F, Martinet O, Ganster F, Navellou JC, Castelain V, Barraud D, Cousson J, Louis G, Perez P, Kuteifan K, Noirot A, Badie J, Mezher C, Lessire H, Pavon A, Study Group E: The epidemiology of septic shock in French intensive care units: the prospective multicenter cohort EPISS study. Crit Care 2013, 17(2):R65. doi: 10.1186/cc12598. PMID: 23561510.

3. Sakr Y, Lobo SM, Moreno RP, Gerlach H, Ranieri VM, Michalopoulos A, Vincent JL, The SOAP Investigators: Patterns and early evolution of organ failure in the intensive care unit and their relation to outcome. Crit Care 2012, 16(6):R222. doi: 10.1186/cc11868. PMID: 23158219.

4. Marshall JC: Clinical trials of mediator-directed therapy in sepsis: What have we learned? Intensive Care Med 2000, 26(Suppl 1):S75-S83. doi: 10.1007/s001340051122. PMID: 10786962.

5. Christaki $E$, Anyfanti P, Opal SM: Immunomodulatory therapy for sepsis: an update. Expert Rev Anti Infect Ther 2011, 9(11):1013-1033. doi: 10.1586/ eri.11.122. PMID: 22029521.
6. Kruger P, Bailey M, Bellomo R, Cooper DJ, Harward M, Higgins A, Howe B, Jones D, Joyce C, Kostner K, McNeil J, Nichol A, Roberts MS, Syres G, Venkatesh B, ANZ-STATInS Investigators-ANZICS Clinical Trials Group: A multicenter randomized trial of atorvastatin therapy in intensive care patients with severe sepsis. Am J Respir Crit Care Med 2013, 187(7):743-750. doi: 10.1164/rccm.201209-17180C. PMID: 23348980.

7. Ranieri VM, Thompson BT, Barie PS, Dhainaut JF, Douglas IS, Finfer S, Gardlund B, Marshall JC, Rhodes A, Artigas A, Payen D, Tenhunen J, Al-Khalidi HR, Thompson V, Janes J, Macias WL, Vangerow B, Williams MD, PROWESS-SHOCK Study Group: Drotrecogin alfa (activated) in adults with septic shock. N Engl J Med 2012, 366(22):2055-2064. doi: 10.1056/NEJMoa1202290. PMID: 22616830.

8. Armour J, Tyml K, Lidington D, Wilson JX: Ascorbate prevents microvascular dysfunction in the skeletal muscle of the septic rat. J Appl Physiol 2001, 90(3):795-803. PMID: 11181585.

9. Wu F, Wilson JX, Tyml K: Ascorbate protects against impaired arteriolar constriction in sepsis by inhibiting inducible nitric oxide synthase expression. Free Radic Biol Med 2004, 37(8):1282-1289. doi:10.1016/j. freeradbiomed.2004.06.025. PMID: 15451067.

10. Fisher BJ, Seropian IM, Kraskauskas D, Thakkar JN, Voelkel NF, Fowler AA 3rd, Natarajan R: Ascorbic acid attenuates lipopolysaccharide-induced acute lung injury. Crit Care Med 2011, 39(6):1454-1460. doi: 10.1097/ CCM.0b013e3182120cb8. PMID: 21358394.

11. Fisher BJ, Kraskauskas D, Martin EJ, Farkas D, Wegelin JA, Brophy D, Ward KR, Voelkel NF, Fowler AA 3rd, Natarajan R: Mechanisms of attenuation of abdominal sepsis induced acute lung injury by ascorbic acid. Am J Physiol Lung Cell Mol Physiol 2012, 303(1):L20-L32. doi: 10.1152/ ajplung.00300.2011. PMID: 22523283.

12. Fisher BJ, Kraskauskas D, Martin EJ, Farkas D, Puri P, Massey HD, Idowu MO, Brophy DF, Voelkel NF, Fowler AA 3rd, Natarajan R: Attenuation of sepsis-induced organ injury in mice by vitamin C. J Parenter Enteral Nutr. in press. [Epub ahead of print] PMID: 23917525 doi: 10.1177/ 0148607113497760

13. Borrelli E, Roux-Lombard P, Grau GE, Girardin E, Ricou B, Dayer JM, Suter PM: Plasma concentrations of cytokines, their soluble receptors, and antioxidant vitamins can predict the development of multiple organ failure in patients at risk. Crit Care Med 1996, 24(3):392-397. PMID: 8625625 Accession: 00003246-199603000-00006.

14. Galley HF, Davies MJ, Webster NR: Ascorbyl radical formation in patients with sepsis: effect of ascorbate loading. Free Rad Biol Med 1996, 20(1):139-143. doi: 10.1016/0891-5849(95)02022-5. PMID: 8903690.

15. Padayatty SJ, Sun H, Wang Y, Riordan HD, Hewitt SM, Katz A, Wesley RA, Levine M: Vitamin C pharmacokinetics: implications for oral and intravenous use. Ann Intern Med 2004, 140(7):533-537. doi: 10.7326/00034819-140-7-200404060-00010. PMID: 15068981.

16. Nathens AB, Neff MJ, Jurkovich GJ, Klotz P, Farver K, Ruzinski JT, Radella F, Garcia I, Maier RV: Randomized, prospective trial of antioxidant supplementation in critically ill surgical patients. Ann Surg 2002, 236(6):814-822. PMID: 12454520 Accession: 00000658-200212000-00014.

17. Tanaka H, Matsuda T, Miyagantani Y, Yukioka T, Matsuda H, Shimazaki S: Reduction of resuscitation fluid volumes in severely burned patients using ascorbic acid administration: a randomized, prospective study. Arch Surg 2000, 135(3):326-331. doi: 10.1001/archsurg.135.3.326. PMID: 10722036.

18. Sawyer MAJ, Mike JJ, Chavin K: Antioxidant therapy and survival in ARDS [abstract]. Crit Care Med 1989, 17:S153.

19. Vincent JL, Donadello K, Schmit X: Biomarkers in the critically ill patient: C-reactive protein. Crit Care Clin 2011, 27(2):241-251. doi: 10.1016/j. ccc.2010.12.010. PMID: 21440199.

20. Jensen JU, Heslet L, Jensen TH, Espersen K, Steffensen P, Tvede M: Procalcitonin increase in early identification of critically ill patients at high risk of mortality. Crit Care Med 2006, 34(10):2596-2602. doi: 10.1097/01.CCM.0000239116.01855.61. PMID: 16915118.

21. Karlsson S, Heikkinen M, Pettilä V, Alila S, Väisänen S, Pulkki K, Kolho E, Ruokonen E, The Finnsepsis Study Group: Predictive value of procalcitonin decrease in patients with severe sepsis: a prospective observational study. Crit Care 2010, 14(6):R205. doi: 10.1186/cC9327. PMID: 21078153.

22. Fowler AA, Fisher BJ, DeWilde C, Priday A, Syed A, Farthing CA, Larus TL, Knowlson S, Natarajan R: Parenteral vitamin C attenuates markers of organ injury and inflammation in severe sepsis [abstract]. Am J Respir Crit Care Med 2012, 185(2012):A6718. 
23. Muckart DJ, Bhagwanjee S: American College of Chest Physicians/Society of Critical Care Medicine Consensus Conference definitions of the systemic inflammatory response syndrome and allied disorders in relation to critically injured patients. Crit Care Med 1997, 25(11):1789-1795. PMID: 9366759 Accession: 00003246-199711000-00014.

24. Urbaniak GC, Plous S: Research randomizer (version 3.0). 2010 http://www.randomizer.org.

25. Harris PA, Taylor R, Thielke R, Payne J, Gonzalez N, Conde JG: Research electronic data capture (REDCap) - a metadata-driven methodology and workflow process for providing translational research informatics support. J Biomed Inform 2009, 42(2):377-381. doi: 10.1016/j.jbi.2008.08.010. PMID: 18929686

26. Vincent JL, Moreno R, Takala J, Willatts S, De Mendonca A, Bruining H, Reinhart CK, Suter PM, Thijs LG: The SOFA (Sepsis-related Organ Failure Assessment) score to describe organ dysfunction/failure. On behalf of the Working Group on Sepsis-Related Problems of the European Society of Intensive Care Medicine. Intensive Care Med 1996, 22(7):707-710. PMID: 8844239.

27. Ferreira FL, Bota DP, Bross A, Melot C, Vincent JL: Serial evaluation of the SOFA score to predict outcome in critically ill patient. JAMA 2001, 286(14):1754-1758. doi: 10.1001/jama.286.14.1754. PMID: 11594901.

28. Beale RJ, Sherry T, Lei K, Campbell-Stephen L, McCook J, Smith J, Venetz W, Alteheld B, Stehle P, Schneider H: Early enteral supplementation with key pharmaconutrients improves sequential organ failure assessment score in critically ill patients with sepsis: outcome of a randomized, controlled, double-blind trial. Crit Care Med 2008, 36(1):131-144. doi: 10.1097/01.CCM.0000297954.45251.A9. PMID: 18007263

29. Moreno R, Vincent JL, Matos R, Mendonca A, Cantraine F, Thijs L, Takala J, Sprung $C$, Antonelli M, Bruining $H$, Willatts $S$ : The use of maximum SOFA score to quantify organ dysfunction/failure in intensive care. Results of a prospective, multicenter study. Working group on sepsis related problems of the ESICM. Intensive Care Med 1999, 25(7):686-696.

30. Hoffer LJ, Levine M, Assouline S, Melnychuk D, Padayatty SJ, Rosadiuk K, Rousseau C, Robitaille L, Miller WH Jr: Phase I clinical trial of i.v. ascorbic acid in advanced malignancy. Ann Oncol 2008, 19(11):1969. PMID: 18544557 doi: 10.1093/annonc/mdn377.

31. Schorah CJ, Downing C, Piripitsi A, Gallivan L, Al-Hazaa AH, Sanderson MJ, Bodenham A: Total vitamin C, ascorbic acid, and dehydroascorbic acid concentrations in plasma of critically ill patients. Am J Clin Nutr 1996, 63(5):760-765. PMID: 8615361.

32. Zhou G, Kamenos G, Pendem S, Wilson JX, Wu F: Ascorbate protects against vascular leakage in cecal ligation and puncture-induced septic peritonitis. Am J Physiol Regul Integr Comp Physiol 2012, 302(4):R409-R416. doi: 10.1152/ajpregu.00153.2011. PMID: 22116513.

33. Wu F, Schuster DP, Tyml K, Wilson JX: Ascorbate inhibits NADPH oxidase subunit p47phox expression in microvascular endothelial cells. Free Radic Biol Med 2007, 42(1):124-131. doi: 10.1016/j.freeradbiomed.2006.10.033. PMID: 17157199.

34. Lobo SM, Lobo FR, Bota DP, Lopes-Ferreira F, Soliman HM, Melot C, Vincent $J \mathrm{~L}$ : C-reactive protein levels correlate with mortality and organ failure in critically ill patients. Chest 2003, 123(6):2043-2049. doi: 10.1378/ chest.123.6.2043. PMID: 12796187

35. Ito T, Maruyama I: Thrombomodulin: protectorate God of the vasculature in thrombosis and inflammation. J Thromb Haemost 2011(9 Suppl 1):168-173. PMID: 21781252 doi: 10.1111/j.1538-7836.2011.04319.

36. Lin $S M$, Wang $Y M$, Lin HC, Lee KY, Huang CD, Liu CY, Wang CH, Kuo HP: Serum thrombomodulin level relates to the clinical course of disseminated intravascular coagulation, multiorgan dysfunction syndrome, and mortality in patients with sepsis. Crit Care Med 2008, 36(3):683-689. doi: 10.1097/CCM.0B013E31816537D8. PMID: 18431261

37. Carcamo JM, Pedraza A, Borquez-Ojeda O, Golde DW: Vitamin C suppresses TNF alpha-induced NF kappa B activation by inhibiting I kappa B alpha phosphorylation. Biochemistry 2002, 41(43):12995-13002. doi: 10.1021/ bi0263210. PMID: 12390026.

38. Vincent JL, Sakr Y, Sprung CL, Ranieri VM, Reinhart K, Gerlach H, Moreno R, Carlet J, Le Gall JR, Payen D, Sepsis Occurrence in Acutely III Patients Investigators: Sepsis in European intensive care units: results of the SOAP study. Crit Care Med 2006, 34(2):344-353. doi: 10.1097/01. CCM.0000194725.48928.3A. PMID: 16424713
39. Finfer S, Bellomo R, Lipman J, French C, Dobb G, Myburgh J: Adult-population incidence of severe sepsis in Australian and New Zealand intensive care units. Intensive Care Med 2004, 30(4):589-596. doi: 10.1007/s00134-004-2157-0. PMID: 14963646.

40. Silva E, Pedro Mde A, Sogayar AC, Mohovic T, Silva CL, Janiszewski M, Cal RG, de Sousa EF, Abe TP, de Andrade J, de Matos JD, Rezende E, Assuncao M, Avezum A, Rocha PC, de Matos GF, Bento AM, Correa AD, Vieira PC, Knobel E, Brazilian Sepsis Epidemiological Study: Brazilian Sepsis Epidemiological Study (BASES study). Crit Care 2004, 8(4):R251-R260. doi: 10.1186/cc2892. PMID: 15312226.

doi:10.1186/1479-5876-12-32

Cite this article as: Fowler et al:: Phase I safety trial of intravenous ascorbic acid in patients with severe sepsis. Journal of Translational Medicine 2014 12:32.

\section{Submit your next manuscript to BioMed Central and take full advantage of:}

- Convenient online submission

- Thorough peer review

- No space constraints or color figure charges

- Immediate publication on acceptance

- Inclusion in PubMed, CAS, Scopus and Google Scholar

- Research which is freely available for redistribution

Submit your manuscript at www.biomedcentral.com/submit
C) Biomed Central 